\title{
Environment protection during mining in the Russian Arctic: modern trends and perspectives
}

\author{
Violetta Gassiy ${ }^{1 *}$, and Vasiliy Stoikov ${ }^{2}$ \\ ${ }^{1}$ Kuban State University, Public administration department, 350040 Krasnodar Russia \\ ${ }^{2}$ Moscow State University of Civil Engineering (National Research University), 129337, Moscow, \\ Russia
}

\begin{abstract}
The paper is devoted to the fundamental issues of the environment protection and mining in the Arctic territory. The author considers the main trends of the industrial development and its impact on the specific ecosystem of the Arctic. The newest laws adopted in the Russian Federation on Arctic development and state policy is researched. In the paper the analysis of the data on the investment to the environment protection in Russia is also performed. It allows developing recommendations for the improvement of environment protection including organizational, legal and scientific measures. The author also researches the industrial development impact on human living conditions and health decreased by the worsening environment of the Arctic. In the paper the necessity of the partnership and cooperation between subsoil user, government and local communities (including indigenous peoples) is justified. The recommendations given in the conclusions include the community councils' formation for the monitoring the quality of the environment on the local level. It could help to prevent conflicts in the Arctic during mining. Other recommendations consider possible ways for the improvement of state policy in the Arctic as well as the mechanisms of the environment economics.
\end{abstract}

\section{Introduction}

Currently, the Arctic is facing the global challenges related to the climate change, industrial development, and the transformation of human activity. The climate change entails the melting of permafrost, a change in the amount of precipitation, a decrease in the amount of the sea ice. The changes in the sea ice concentration have both positive and negative effects. Among the positive aspects, one can note the accessibility of the Northern Sea Route, its all-seasons character for a wide type of vessels. Its negative impact connects with catastrophic effect on human activities in the Arctic, the life of indigenous peoples, soil degradation and the destruction of infrastructure. Recent studies show that the Arctic ecology is improving in certain regions in Russia. In the rest, where mining and processing

\footnotetext{
*Corresponding author: vgassiy@mail.ru
} 
industries are presented, the level of pollution is growing. Especially the environment is affected by industrial economic activity, i.e. mining. According to The US Geological Survey, about $30 \%$ of unexplored gas reserves are in the Arctic [1]. Despite the fact that environmental requirements for investment projects are tightening on, the threat of disturbing the ecological balance in the fragile Arctic system remains.

To a greater extent, industrial facilities affect human health. Pollution of the atmosphere, sea and river waters, soils has a negative impact on the livelihoods of people, their way and quality of life. To prevent imbalance in nature organizational, economic and legal instruments of state regulation are used. Organizational tools establish the rules of environmental impact assessment, environmental damage assessment, and environmental control. The economic approach includes payments for the use of natural resources, payments for pollution, financing of measures to eliminate damage or its prevention. Environmental law establishes liability for environmental pollution, the procedure for damages, regulates access to information about investment projects and their potential impact on the environment. With this in mind, the industrial development of the Arctic is a complex task that can only be implemented with strict rules and procedures for the conservation of a unique ecosystem.

\section{Materials and Methods}

One of the main tasks to ensure the environmental security of the Arctic is the elimination of accumulated damage from economic activity. The greening of production and the economy as a whole is a priority in the implementation of the state policy of any developed state. The anthropogenic load of the Arctic landscape is increasing, and, therefore, the issue of accelerating the process of restoring the disturbed ecological balance is an important element of industrial development. When developing approaches to environmental protection, it is necessary to take into account the specifics of the Arctic ecosystem: special harsh natural conditions and traditional nature management, which forms the basis of indigenous peoples' life in the Arctic. These factors determine the types of technologies used both in relation to water resources and land. It should be noted that due to the imperfection of legislation in the field of eliminating accumulated environmental damage, mining companies are not interested in an objective assessment of its size, since its scope is often significant. Various methods are currently being used to analyze the level of negative impact, including remote sensing, satellite imagery, sampling, and recording violations by the local population. In some regions of Russia, approaches are used to assess the amount of compensation for the negative impact of the investment project on the ethnological environment of indigenous peoples. For example, in Yakutia since 2010, a law on ethnological expertise has been in force [9].

At the beginning of the research on environmental problems during the industrial development of the Arctic, it is necessary to formulate a hypothesis based on previously accumulated facts. A hypothesis is considered as a scientific assumption about a natural causal relationship that causes certain facts or phenomena. The results of the research depend on the advancement of the working hypothesis, its correctness. The research hypothesis considers critical importance of the innovations for Arctic sustainable development, ecosystem benefits, leading to the improvement in the quality of life of the local population. As a result of industrial development of the Arctic, the environment is deteriorating, soil, air and water are being polluted. The innovations implementation at the industrial enterprises, as well as increasing environmental requirements for planned investment projects, can positively affect the environment.

In the paper, the authors also used the statistical-economic method. The statistical and economic research method is a set of techniques used to comprehensively characterize the 
development of economic phenomena and processes using massive digital data. The following stages of statistical and economic research used in the article:

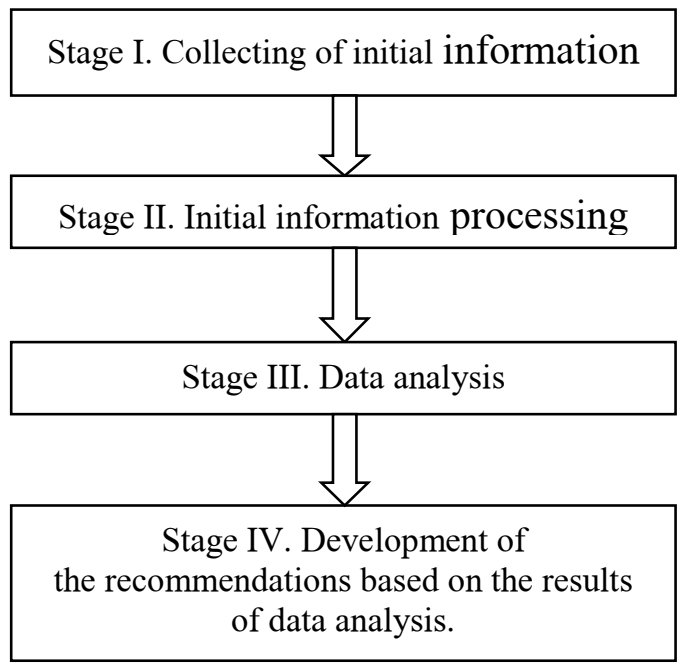

Fig.1. The sequence of the research methods

As a rule, the statistical-economic research method is used in the study of social phenomena and processes that occur in the lives of people and society. To study the phenomena and processes, it is necessary to consider all factors that make up the process or phenomenon. Therefore, in the paper the comprehensive approach for considering the problem of environmental protection is used. As statistical data, dynamic series are used, i.e. indicators characterizing the change in the phenomenon over time. The authors of the article also use comparison as a research method. It should be noted that comparison is one of the most important and most common methods for studying the relationships in socio-economic development. It begins with an analysis of the functioning of economic sectors, spheres of public life, and environmental parameters could be also evaluated. An indispensable condition for comparison is the comparability of indicators. Bringing data to a comparable form is achieved by selecting and appropriately processing indicators, recalculating data using the same methodology, converting data to one unit of measurement, and extracting a homogeneous population from the entire mass of data.

\section{Results and Discussion}

In recent years, laws on state policy in the Arctic have been adopted at the state level in the Russian Federation. In March 2020, Russian President Vladimir Putin signed a decree approving the foundations and priority areas of the Arctic development. This document defines the national interests of the country in the strategically significant northern region. Among them:

The national interests of the Russian Federation in the Arctic are:

a) Ensuring the sovereignty and territorial integrity of the Russian Federation;

b) The preservation of the Arctic as a territory of the piece, a stable and mutually beneficial partnership;

c) Ensuring a high quality of life and well-being of the population of the Arctic; 
d) The development of the Arctic as a strategic resource base and its rational use in order to accelerate the economic growth of the Russian Federation;

e) Development of the Northern Sea Route as a competitive national transport communication of the Russian Federation on the world market;

f) Environmental protection in the Arctic, protection of the original habitat and traditional lifestyle of indigenous peoples living in the Arctic zone of the Russian Federation [2].

It should be noted that environmental protection is closely related to the issue of national security and the development of mineral reserves. In addition to the enormous hydrocarbon reserves located in the Arctic regions, Russia also possesses about $10 \%$ of the world's active nickel reserves, about $19 \%$ of the platinum group metals (PGM), $10 \%$ of titanium, more than $3 \%$ of zinc, cobalt, gold and silver [3]. The largest investment projects are currently being implemented using advanced technologies and taking into account modern environmental requirements. For example, the Yamal LNG project pays great attention to the environmental management taking into account the requirements of the international standards ISO 14001: 2004 and OHSAS 18001: 2007. Also, the company implementing this mining project has undertaken the obligations [4]:

- To prevent environmental pollution and minimize anthropogenic pressure on the environment, managing environmental aspects in the process of production activities;

- Ensure resource conservation, minimize negative impact on the environment, take all possible measures to preserve climate, biodiversity and compensate for possible damage to the environment;

- To conduct business in strict accordance with legislative, corporate and other requirements that have been accepted as mandatory by ourselves in the field of occupational safety, labour protection and environmental protection;

- Take into account the interests and rights of indigenous minorities to maintain a traditional lifestyle, preservation of the original habitat and cultural traditions.

An important component of the research on the role of mining in the Arctic development is the study of the specificity of increased industrial development in these remote territories. The extraction of natural resources in the Arctic is characterized by the complexity associated with harsh climatic conditions, the need to operate at extreme temperatures, improve geological exploration technology, and the use of innovative equipment. Significant subsoil user costs are associated with the use of green technologies aimed at the energy efficiency, resource conservation, and environmental protection [5].

Ensuring the environmental safety of the Arctic region is part of Russia's environmental security strategy. In 2017, Russia adopted the Environmental Security Strategy, the main goals of which are the preservation and protection of the country's natural wealth. Among the environmental protection measures, it is planned to eliminate the negative consequences of the impact of anthropogenic factors on the environment, rehabilitation of the territories and water areas contaminated as a result of economic and other activities; minimization of damage to the environment during exploration and mining of minerals [6]. The need to adopt a strategy is justified by the fact that, according to experts, every year economic losses due to environmental degradation make up 4-6 percent of the gross domestic product, and this does not take into account damage to human health.

The data of the Federal State Statistics Service indicate that companies' investments in environmental protection and environmental management are increasing annually, fig.2 [7]: 


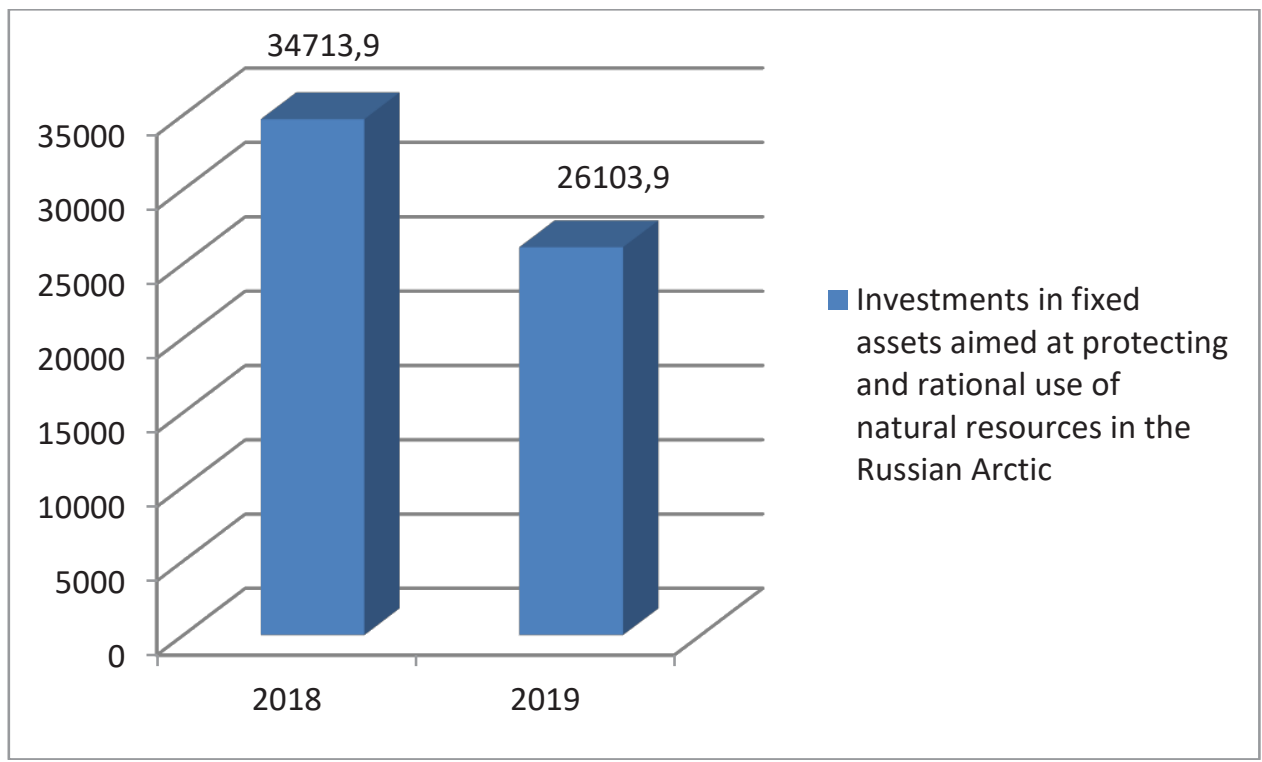

Fig.2 Investments in fixed assets aimed at protecting and rational use of natural resources in the Russian Arctic, mln rubles.

Source: Federal State Statistics Service, 2019

Analysis of the structure of investments in environmental protection measures shows that the largest amount of financial resources is directed to the elimination of air pollution, fig. 3 [7]:

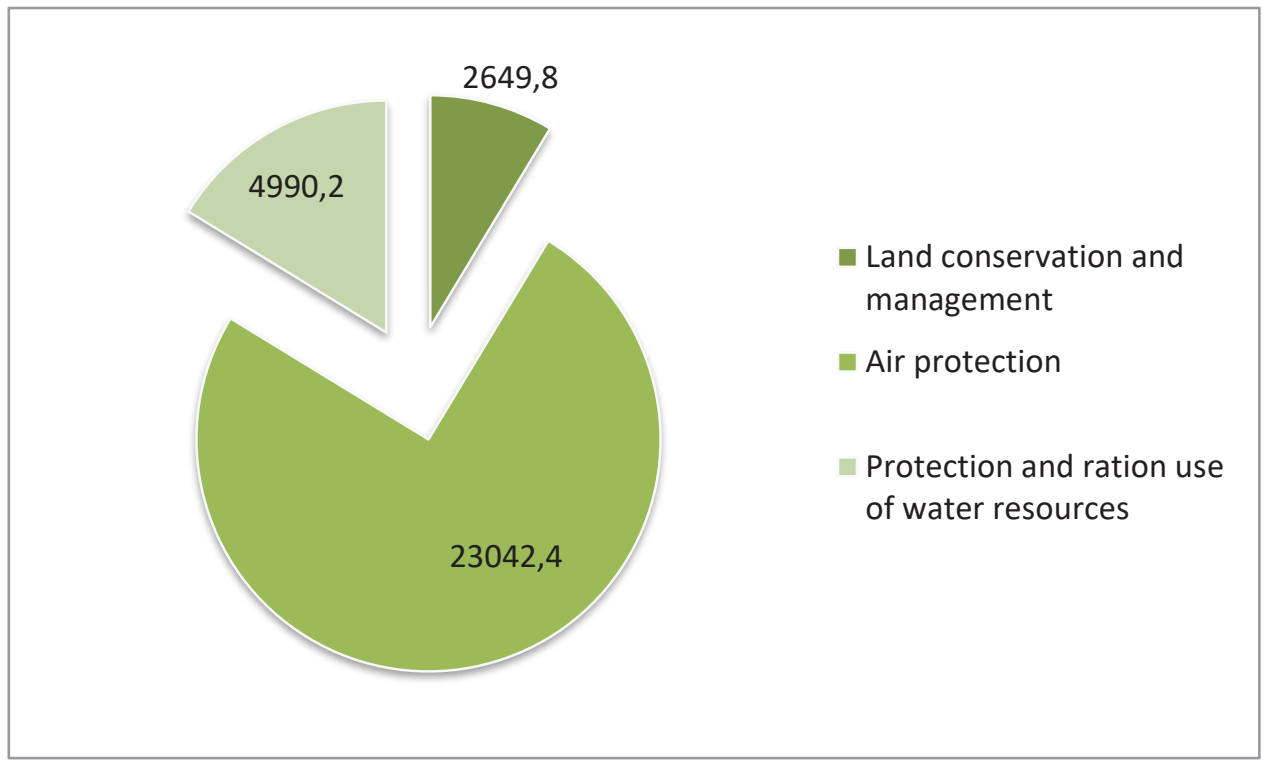

Fig. 3. The structure of investments aimed at protecting and rational use of natural resources in the Russian Arctic, thousand rubles

Source: Federal State Statistics Service, 2019 
Industrial enterprises are the main sources of negative impact on the atmosphere in the Arctic regions [8]. Moreover, environmental control is significantly late for the industrial development of the Arctic territories. In Russia, it is planned to equip settlements with air pollution monitoring stations during 2021-2025 as a part of the implementation of the state program for the socio-economic development of the Arctic. As a rule, where large industrial enterprises are located (mining, chemical, pulp and paper, etc.), the concentration of maximum permissible values is significantly exceeded. A promising area is to attract business to the process of monitoring air quality. Nowadays the state meteorological stations are not enough, some of them are mothballed. Therefore, in order to increase the efficiency of air quality monitoring, cooperative ties should be formed with industrial enterprises that could independently collect data.

To effectively manage changes in the ecosystem of the Arctic, it is necessary to create a unified monitoring platform to track the crisis phenomena that occur in nature and due to anthropogenic impact. This will allow timely response to Arctic transformations, predict the behavior of various objects. One of the most important issues remains the difference in the climate change in the Arctic regions of Russia. This is due to the heterogeneity of approaches to the implementation of industrial activities and the development of natural resources. For example, earlier melting of ice in rivers leads to a reduction in winter paths, complicates production logistics, and increases the threat to human activity in the Arctic. On the other hand, there are regions of the country where the average annual temperatures are decreasing, which forces mining companies to change their strategies.

\section{Conclusions}

Thus, intensive industrial development of the Arctic leads to the degradation of a fragile ecosystem. Further subsoil use on the continental shelf and the mainland of the Arctic can lead to regional or even global environmental threats. An adequate response to environmental risks is the improvement of geological exploration and mining technologies. It is important to improve the legal framework for environmental protection during industrial development. It should be noted that in other Arctic countries there is specialized legislation regarding industrial activities in the Arctic and environmental protection. For example, in Norway there is a law on the protection of nature on Spitsbergen, and in Canada there is a separate legislation on the development of the Arctic seas, the organization of specially protected natural territories there. To improve legislation in Russia, it is necessary to provide mechanisms to stimulate innovative activity of enterprises with the aim of introducing resource-saving technologies, purification and collection systems for water and air purification.

The analysis showed that to ensure the environmental safety of the Arctic regions during industrial development, it is necessary to improve the organizational, legal and scientific foundations of economic activity. Organizationally, it is necessary to improve the infrastructure of the Northern Sea Route, create centers along the entire route for prompt response to emergencies and eliminate their consequences, develop a system of specially protected natural areas to preserve the biodiversity of the Arctic zone. It is also necessary to expand the interaction of the state, business and the people of the Arctic. In particular, in traditional lands, it is possible to develop a system of public monitoring, partnership mechanisms of business and local communities to prevent conflicts. In the legal aspect, it is necessary to improve the mechanisms for eliminating accumulated environmental damage, review the methods for assessing it, to introduce environmental insurance and other methods to ensure financial risks in the development of the Arctic mineral resources. The scientific approach to environmental safety of the Arctic territories should include the development of innovative technologies for geological exploration and mining, improving 
the methodology for studying the interaction of human being and nature, environmental damage assessment for each type of economic activity, for each type of resource. This will save the environment of the Arctic during its industrial development.

\section{Acknowledgments}

The paper was prepared by the financial support of the grant of the President of the Russian Federation for state support of young Russian scientists - doctors MD-402.2019.6.

\section{References}

1. D. L. Gautier, K.J. Bird, R.R. Charpentier, A. Grantz, D.W. Houseknecht, T.R. Klett, T. E. Moore, J. K. Pittman, et al., Assessment of undiscovered oil and gas in the Arctic. Science, 324, 1175-1179 (2009)

2. Decree of the President of the Russian Federation dated, 164, 03.05.2020, URL: http://publication.pravo.gov.ru/Document/View/0001202003050019

3. S. V. Krivovichev, Arctic Mineral Resources: Science and Technology, Minerals, 9, 192, (2019) doi:10.3390/min9030192

4. Ecology, OJSC Yamal LNG. URL: http://yamallng.ru/progress/ecology-new/

5. Anne Tolvanena, Pasi Eilu, Artti Juutinena Katja Kangasa Mari Kivinen Mira Markovaara-Koivistoc Arto Naskalie, Veera Salokannel, Seija Tuulentie, Jukka Simila, Journal of Environmental Management, 233, 832-844 (2019) https://doi.org/10.1016/j.jenvman.2018.11.124

6. V. Gassiy, V. Stoikov, Development of a green economy and environmentally friendly business in Russia, E3S Web Conf., 110, 02069 (2019) https://doi.org/10.1051/e3sconf/201911002069

7. Federal State Statistics Service, (2019) URL: https://www.gks.ru/free_doc/new_site/region_stat/calendar1-2020.htm

8. K. S. Law, A. Roiger, J. L. Thomas, [et al.], Local Arctic air pollution: Sources and impacts. Ambio; 46 (Suppl 3), 453-463 (2017) doi: 10.1007 / s13280-017-0962-2

9. V. Gassiy, I. Potravny, The Compensation for Losses to Indigenous Peoples Due to the Arctic Industrial Development in Benefit Sharing Paradigm. Resources, 8, 71 (2019) https://doi.org/10.3390/resources8020071 